\title{
The chaos of times and the precision of times
}

It was the worst of year and it was the best of year! This year, the pandemic caused the chaos and hold us together. This year, we also stand together to fight the cancer with precision. This special series focuses on precision medicine for cancer and tries to bring more ideas on future prospects.

Knowledge, research, and technology bring more options to cancer treatment. Along with rapid development of computer science, molecular biology, and nanoparticle investigation, cancer treatment also evolves. Surgeons utilize da Vinci Si Surgical System to decrease operation injury. Medical oncologists treat patients with target therapy and immunotherapy according to individual cancer molecule expressions. As for radiotherapy, we also take few further steps in this ever-changing era.

Radiotherapy provides better solutions both in treatment approaches and prognosis prediction by technology and science evolution. In the Dr. Hung's study, the value of Albumin-Bilirubin (ALBI) score could predict the risk of radiation-induced liver disease in hepatocellular carcinoma patients that allows us to deliver radiation dose more precisely and avoids undesired damage. Furthermore, Dr. Huang uses the radiomics to link the peritumoral region in HCC to the outcome after stereotactic body radiation therapy (SBRT), opening the possibility of combined immunotherapy. Notably, Dr. Choi discussed the future of proton therapy (PT) from different points, such as dosimetric advantages, better preserve quality of life and disease control benefits, that provided more clear view of how this technology will best be applied and integrated into the field in the future. Additionally, Dr. Chen provided the successful case treated by boron neutron capture therapy and discussed the important issue about how to contain boron in cancer cells and elevate the tumor-to-normal ratio remains. Specifically, Dr. Chuong reported the application of MR-guided linear accelerators (LINACs) for oligometastatic cancer by SBRT with treasure and successful experiences. Interestingly, Dr. Chien reported the correlation about abscopal effect and white blood cell (WBC) count that mention the potential role of RT for the integrated-precision treatment. Moreover, patient with optic nerve sheath meningioma was treated by noncoplanar volumetric modulated arc therapy focusing on the 0.8 -cm diameter of tumor on the optic nerve with encouraged result that explores the accuracy of modern radiotherapy.

Radiotherapy is on the way of re-revolution, as we investigate more, as more possibility of radiotherapy that can be explored. Hope this special series sheds light on our understanding of radiotherapy in the precision medicine and brings more ideas to integrate radiotherapy into cancer care.

\section{Acknowledgments}

Funding: None.

\section{Footnote}

Provenance and Peer Review: This article was commissioned by the editorial office, Therapeutic Radiology and Oncology for the series "Precision Medicine for Cancer". The article did not undergo external peer review.

Conflicts of Interest: All authors have completed the ICMJE uniform disclosure form (available at http://dx.doi.org/10.21037/ tro-2019-pmc-08). The series "Precision Medicine for Cancer" was commissioned by the editorial office without any funding or sponsorship. CHH, HHN and YMH served as the unpaid Guest Editors of the series. CHH serves as an unpaid editorial board member of Therapeutic Radiology and Oncology from May 2020 to Apr 2022. The authors have no other conflicts of interest to declare.

Ethical Statement: The authors are accountable for all aspects of the work in ensuring that questions related to the accuracy or integrity of any part of the work are appropriately investigated and resolved.

Open Access Statement: This is an Open Access article distributed in accordance with the Creative Commons AttributionNonCommercial-NoDerivs 4.0 International License (CC BY-NC-ND 4.0), which permits the non-commercial replication 
and distribution of the article with the strict proviso that no changes or edits are made and the original work is properly cited (including links to both the formal publication through the relevant DOI and the license). See: https://creativecommons.org/ licenses/by-nc-nd/4.0/.

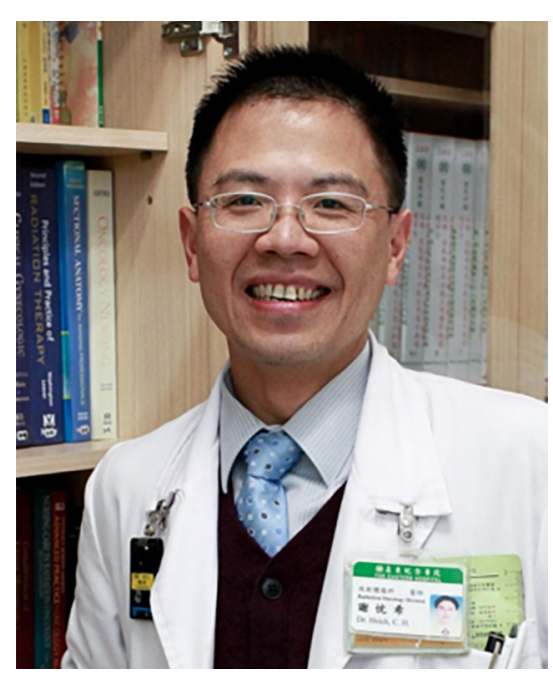

Chen-Hsi Hsieh

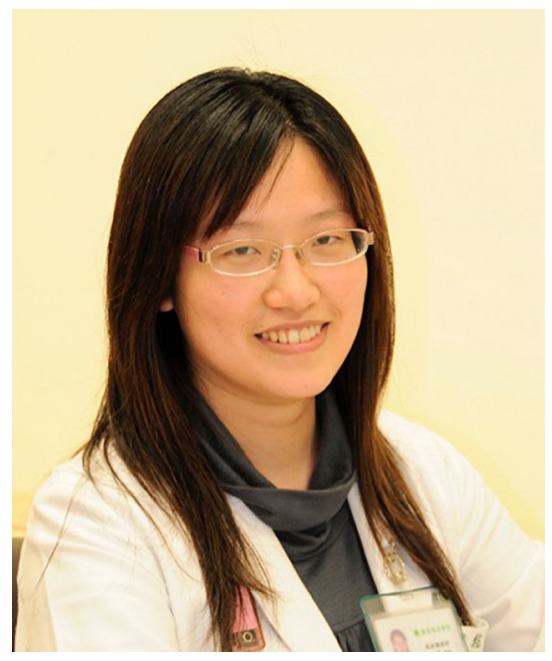

Hsin-Hua Nien

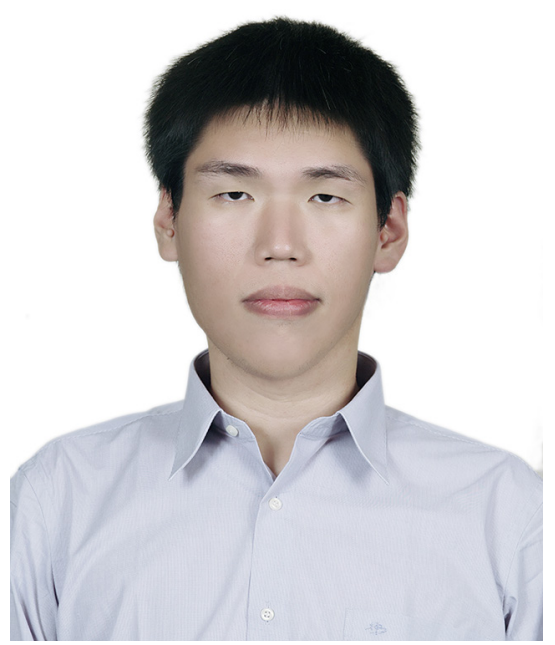

Yu-Ming Huang

Chen-Hsi Hsieh, MD, PHD ${ }^{1,2,3}$

${ }^{1}$ Division of Radiation Oncology, Department of Radiology, Far Eastern Memorial Hospital, Taipei, Taiwan; ${ }^{2}$ Department of Medicine, Institute of Traditional Medicine, School of Medicine, National Yang-Ming University, Taipei, Taiwan.

(Email: chenciab@gmail.com)

Hsin-Hua Nien ${ }^{4}$

${ }^{4}$ Department of Radiation Oncology, Cathay General Hospital, Taipei, Taiwan. (Email: cgh10370@cgh.org.tw)

Yu-Ming Huang ${ }^{5}$

${ }^{5}$ Department of Radiation Oncology, MacKay Memorial Hospital, Taiwan. (Email: vin301.tw@yahoo.com.tw)

Received: 13 October 2020; Accepted: 30 October 2020; Published: 30 December 2020.

doi: 10.21037/tro-2019-pmc-08

View this article at: http://dx.doi.org/10.21037/tro-2019-pmc-08

doi: $10.21037 /$ tro-2019-pmc-08

Cite this article as: Hsieh $\mathrm{CH}$, Nien HH, Huang YM. The chaos of times and the precision of times. Ther Radiol Oncol $2020 ; 4: 24$. 